\title{
Amazônia: defesa e segurança de região prioritária
}

\section{Amazon: defense and security priority region}

\author{
Adriana Iop Bellintani ${ }^{1}$
}

Américo de Lira ${ }^{2}$

\section{Resumo}

Este trabalho versa sobre a segurança e a defesa da fronteira Amazônica, em especial, durante a Operação Ágata 4 realizada entre os dias 02 e 17 de maio de 2012 na Amazônia setentrional. A operação, estruturada pelas diretrizes da Estratégia Nacional de Defesa e pelo Plano Estratégico de Fronteiras, ocorreu na fronteira entre o Brasil e os seguintes países: Guiana, Guiana Francesa, Suriname e Venezuela. Entre os objetivos do Governo Federal, das Forças Armadas e dos órgãos de segurança pública estava a contenção dos ilícitos transnacionais na região. A Amazônia possui pluralidade de contextos e é área prioritária para o Estado Brasileiro.

Palavras chaves: Amazônia, Fronteira e Defesa.

\begin{abstract}
This work focuses on the security and defense of the Amazon frontier, in particular during operation Ágata 4, that was held from $02^{\text {nd }}$ to May $17^{\text {th }}, 2012$, in Northern Amazonia. The operation, structured by the guidelines of the National Defense Strategy and the Strategic Plan of Borders, occurred on the border between Brazil and the following countries: Guyana, French Guiana, Suriname and Venezuela. Among the objectives of the Federal Government, the armed forces and the public security organs was illicit transnational suppression in the region. Amazon has plurality of contexts and is a priority area for the Brazilian State.
\end{abstract}

Key Words: Amazon, Borders and Defense.

Artigo recebido em: 30/1/2014

Artigo aprovado para publicação em: 05/02/2014

\footnotetext{
1 Adriana Bellintani é doutora em História Social pela Universidade de Brasília, professora da Universidade Federal de Roraima e Coordenadora do Curso de Relações Internacionais da UFRR Email: adrianaiopb@yahoo.com.br

${ }^{2}$ Américo de Lyra é doutor em História pela Universidade de Brasília e professor na Universidade Federal de Roraima. Email: americodelyra@uol.com.br;
}

Revista Eletrônica da ANPHLAC, ISSN 1679-1061, n. 16, p. 6-25, Jan./Jul. 2014.

http://revista.anphlac.org.br 
A Amazônia é uma construção ocidental que não contempla características inerentes à região, como sua vocação ${ }^{3}$ para fazer cooperar e integrar as sociedades andinas e amazônicas. Antes do primeiro contato entre europeus e nativos no século XVI, essas sociedades mantinham, entre si, comércio de toda ordem. Kelerson Semerene Costa (2009, p. 5) indica que recentes estudos arqueológicos revelam que povos andinos e amazônicos mantinham intensas relações, tendo os rios como principal eixo de comunicação. Frisa-se que essa comunicação ligou a serra às áreas mais baixas da floresta, com povos andinos buscando produtos produzidos pelos povos das áreas tropicais.

Segundo Costa (2009, p. 5), aqueles estudos arqueológicos mostram diversos registros da presença de povos amazônicos nas montanhas em períodos pré-incaicos. Mas as relações teriam sido mais intensas ao longo do império inca. Os incas pretendiam incorporar povos e territórios amazônicos, a exemplo do ocorrido no Alto Huallaga (nos afluentes do Alto Madre de Dios e no Alto Beni). Nessa área, foram construídas fortificações estratégicas e militares, com o estabelecimento de colônias. Nestas colônias existiam centros de produção e intercâmbio com as sociedades amazônicas. A despeito do insucesso dos planos de incorporação mencionados, o argumento do autor revela que as sociedades em questão eram relativamente complexas, inclusive as amazônicas.

A ideia de sociedades amazônicas relativamente complexas contraria versões tradicionais sobre o desenvolvimento desses povos. De modo geral, atribui-se a estes povos e sociedades a condição de pouco numerosos, com sociedades nada hierarquizadas e de baixa densidade demográfica. A partir dessa explicação, entende-se que o meio ambiente limitaria os grupos humanos locais, determinando sua falta de desenvolvimento em termos de culturas complexas. Com base em estudos arqueológicos sobre as intensas relações dos povos indígenas amazônicos com os andinos, tem-se que nas áreas de várzea existiram grupos humanos numerosos,

\footnotetext{
${ }^{3}$ Entende-se vocação como as potencialidades de uma região, consideradas a partir das suas condições naturais e do seu desenvolvimento histórico. No caso amazônico, a vocação se relaciona ao curso da bacia do rio Amazonas e aos seus inúmeros rios tributários que determinaram a comunicação e as relações entre as sociedades originárias como atualmente servem aos indígenas e ribeirinhos.
}

Revista Eletrônica da ANPHLAC, ISSN 1679-1061, n. 16, p. 6-25, Jan./Jul. 2014. 
agrupados em sociedades relativamente organizadas e que mantinham densamente povoadas as margens do rio Amazonas.

Alguns povos e sociedades amazônicas, inclusive, promoveram alterações na paisagem natural da floresta. Eles construíram canteiros drenados e elevaram terreno para agricultura, defesa e habitação. De acordo com Costa (2009, p. 5-6), obras que se localizavam em territórios da Bolívia, Brasil, Guiana e Venezuela. Mas que se perderam após a colonização europeia e conforme o desaparecimento dos habitantes originários.

O desaparecimento desses habitantes e dos indicadores dos povos e sociedades mencionadas mostra que a colonização e a ocidentalização da Amazônia se consolidaram. E, ao se consolidar, um novo equilíbrio de poder ${ }^{4}$ emerge na região. Este equilíbrio, por seu turno, não foi pleno porque outras sociedades surgem como herdeiras das anteriores. As sociedades herdeiras dos colonizadores e as que mantêm o legado das colonizadas. Mas, em termos de ocidentalização e pensando em Estados, restam dois problemas. O primeiro se relaciona ao impedimento da vocação de cooperação e integração, como bem coloca Carlos de Meira Matos (1980, p. 22) ao refletir a Amazônia como uniformidade de uma mesma imagem geográfica.

(...) Na realidade isto não acontece. Esta imensa região natural, portadora de ecologia uniforme, abrangendo o território de seis países tributários, é enfocada por seus condôminos [sic] sob uma visão particularizada. Assim é que quando o brasileiro ou o venezuelano, colombiano, peruano, equatoriano ou boliviano refere-se à Amazônia está falando na sua Amazônia.

Os Estados nacionais e os povos e sociedades que encerram, no caso daquele equilíbrio de poder não pleno, perderam a vocação amazônica de cooperação e relações dos habitantes originários. A Amazônia é refletida como território de um único país a despeito da "ecologia uniforme". Aliás, ecologia que não reconhece limites abstratos e humanos de Estado ou fronteiras políticas. Mas, em termos de Estados nacionais, a capacidade de diálogo e ações conjuntas tem-se revelado incipiente e as políticas públicas se limitam a atender as sociedades nacionais e muito mal os povos que se localizam nas fronteiras internacionais dos seus respectivos países.

\footnotetext{
${ }^{4}$ Condição para que os atores envolvidos em uma relação de poder se conservem seguros e afirmem seus valores nessa relação. Essa condição pode ser posta pela força de um ou mais atores ou por consenso entre os membros participantes das relações de poder.
}

Revista Eletrônica da ANPHLAC, ISSN 1679-1061, n. 16, p. 6-25, Jan./Jul. 2014.

http://revista.anphlac.org.br 
Disso resulta um segundo problema, denominado de subdesenvolvimento sustentável por Argemiro Procópio (2008). Para esse autor, a atenção dos gestores dos Estados nacionais que compartilham a bacia do rio Amazonas não atinge a contento a região em pauta. E essa limitação permite que sejam formados "vácuos de poder", bem utilizados por agentes que promovem os ilícitos em fronteiras desprotegidas ou mal protegidas. Associando-se a falta de um equilíbrio de poder pleno na região, então se contemplam exércitos de desafortunados para atender à indústria lucrativa dos ilícitos.

Nessa perspectiva, pode-se afirmar que a região Amazônica possui uma pluralidade de contextos, devido, dentre outras abordagens, à grande diversidade étnicocultural, à extensa área territorial que engloba vários países, à enorme riqueza pouco explorada e à importância estratégica para a defesa nacional, que merece ser estudada e analisada com afinco. Todas essas questões se entrelaçam e transformam a região Amazônica em uma matéria de vivo interesse aos pesquisadores. A região propicia uma grande fonte de material para o historiador que se debruça sobre a cultura, a política, a defesa e a história social da região. Suas grandes diferenças regionais permitem vasto número de pesquisas, tendo em vista que a área ainda é pouco explorada e, consequentemente, merece maior atenção do meio acadêmico.

Conhecer a região Amazônica tem importância estratégica para o Brasil, não só pelo quanto ela representa do território nacional, mas também por seu valor em termos de riquezas e de sua capacidade presente e potencial para contribuir para o desenvolvimento nacional. Conhecê-la e aprofundar o estudo sobre suas representações é imprescindível à sua defesa como parte integrante da nação brasileira.

A política de segurança e defesa, segundo Buzan, está intrinsecamente relacionada ao objetivo maior de cada governo federal. A defesa tem por finalidade garantir a soberania do território nacional, tarefa executada pelas Forças Armadas. O conceito de segurança, atualmente, amplia o sentido tradicional de defesa ao ter como objeto a preocupação com a população e a biodiversidade. No Brasil, a Amazônia é considerada área prioritária pela Estratégia Nacional de Defesa, em virtude de características como biodiversidade, baixa densidade demográfica e extensa área fronteiriça.

Revista Eletrônica da ANPHLAC, ISSN 1679-1061, n. 16, p. 6-25, Jan./Jul. 2014. 
Nessa área existem problemas com crimes transnacionais, ou seja, aqueles que violam as leis de dois ou mais estados. Entre os ilícitos transnacionais, de acordo com Collins, podemos citar lavagem de dinheiro, tráfico de drogas, corrupção pública, infiltração de negócios ilegais, seguros e falências fraudulentas, crimes feitos pela internet, tráfico de armas, terrorismo, sequestro de aeronaves, pirataria, tráfico de pessoas, comércio de órgãos, entre outros.

A Amazônia, segundo Villas Bôas (2010, p.463), ainda não está totalmente integrada à dinâmica do desenvolvimento nacional. Este espaço é fundamental para a liderança continental do Brasil.

A Estratégia Nacional de Defesa (END) confere ampla importância à região, fato que se justifica pelo número de países que englobam esse cenário, o vasto território e as incidências de crimes transnacionais que podem ameaçar a soberania nacional. A END é um dos documentos elaborados pelo Governo Federal para incrementar a discussão do tema defesa na sociedade brasileira.

\section{A Estratégia Nacional de Defesa}

A América do Sul hoje possui alguns conflitos que merecem atenção, tais como a violação do espaço aéreo equatoriano pela Força Aérea da Colômbia para atacar um acampamento das Forças Armadas Revolucionárias da Colômbia (FARC), em primeiro de março de 2008, que gerou a crise da Colômbia (apoiada pelos Estados Unidos) com os vizinhos andinos.

A demarcação de limites na América do Sul ainda está em discussão: Chile e Peru discutem sobre demarcação marítima; Colômbia e Nicarágua discutem a posse das ilhas San Andrés e Providências; a Bolívia apresentou um processo contra o Chile na Corte Internacional de Justiça (CIJ), para reclamar acesso ao Oceano Pacífico; Uruguai e Argentina se indispõem sobre a questão ambiental devido à fábrica Botnia de papel e celulose em Fray Bentos no Uruguai. Ainda existem outras questões menores pendentes como a navegação entre Suriname e Guiana.

Esses problemas e questões demarcatórias não resolvidas geram instabilidade entre os estados no cenário internacional. Chile, Venezuela, Colômbia e Equador aumentaram seus orçamentos militares, fato que gera assimetrias na região, visto que,

Revista Eletrônica da ANPHLAC, ISSN 1679-1061, n. 16, p. 6-25, Jan./Jul. 2014.

http://revista.anphlac.org.br 
de acordo com Gama (2010, p.358), houve "relativo enfraquecimento do poder militar na Argentina."

Nesse contexto sul-americano, a partir de 2002, o Brasil desponta com um ativismo diplomático e, como sugere Paulo Roberto de Almeida (2004), uma política externa engajada. Esta política externa se revela, de acordo com Almeida (2004, p. 162), como a "(...) vertente da atividade governamental que mais reflete as propostas e as posições tradicionais do Partido dos Trabalhadores".

Em linhas gerais, a vertente aludida no parágrafo anterior se apresenta como uma coordenação política mais ativa, a qual possa entabular negociações internacionais com atores independentes do globo, como os países do mundo em desenvolvimento. Neste caso, destacam-se a África do Sul, a China e a Índia. Ou, ainda, a busca de parcerias com os vizinhos da América do Sul.

Essas opções compõem o que o então chanceler Celso Amorim denominava de "diplomacia ativa e altiva", uma vez que a política externa brasileira se apresentava mais propositiva e proativa, propondo novas parcerias e dando maior importância às relações Sul-Sul. A partir desse preâmbulo, no qual se apresenta outra concepção de inserção internacional do Brasil em termos de política externa, a orientação da Estratégia Nacional de Defesa (Decreto $N^{\circ}$ 6. 703, de 18 de dezembro de 2008) indica a percepção da Amazônia em esfera regional.

Compondo tal cenário e considerando a conjuntura internacional, o Brasil elaborou a Estratégia Nacional de Defesa (END) que pontua as prioridades de defesa do Brasil. De acordo com Jungmann (2010, p.478): “a END expressa a necessidade de o Brasil dizer a si mesmo quais os caminhos que pretende trilhar (...) prevalecem eixos que reorganizam as Forças Armadas e que criam condições para desenvolvimento tecnológico autônomo aliado à indústria bélica."

A END defende o monitoramento do espaço terrestre, aéreo e marítimo com uso de tecnologias e fortalece três grandes setores: cibernético, nuclear e espacial. O setor nuclear para fins pacíficos, visto que o Brasil assinou o Tratado de Não Proliferação de Armas Nucleares (1968) e há ainda a Declaração de Cartagena de 1991 que proíbe armas de destruição em massa na América Latina.

Revista Eletrônica da ANPHLAC, ISSN 1679-1061, n. 16, p. 6-25, Jan./Jul. 2014. 
Além de pugnar pela congregação e emprego das forças em conjunto (Exército, Marinha e Aeronáutica), a END, em seu artigo oitavo, aumentou o foco das atenções para a direção norte do país, em um eventual teatro de operações:

As principais unidades do Exército estacionam no Sudeste e no Sul do Brasil. A esquadra da Marinha concentra-se na cidade do Rio de Janeiro. As instalações tecnológicas da Força Aérea estão quase todas localizadas em São José dos Campos, em São Paulo. As preocupações mais agudas de defesa estão, porém, no Norte, no Oeste e no Atlântico Sul.

Sem desconsiderar a necessidade de defender as maiores concentrações demográficas e os maiores centros industriais do País, a Marinha deverá estar mais presente na região da foz do Amazonas e nas grandes bacias fluviais do Amazonas e do Paraguai-Paraná. O Exército deverá posicionar suas reservas estratégicas no centro do País, de onde poderão se deslocar em qualquer direção. Deverá também o Exército agrupar suas reservas regionais nas respectivas áreas, para possibilitar a resposta imediata na crise ou no conflito armado.

No combate aos ilícitos, o governo brasileiro desenvolve a mobilidade e capacidade logística na Amazônia e defende que a guarnição da região é de inteira responsabilidade do Brasil, conforme artigo décimo da END:

O Brasil será vigilante na reafirmação incondicional de sua soberania sobre a Amazônia brasileira. Repudiará, pela prática de atos de desenvolvimento e de defesa, qualquer tentativa de tutela sobre as suas decisões a respeito de preservação, de desenvolvimento e de defesa da Amazônia. Não permitirá que organizações ou indivíduos sirvam de instrumentos para interesses estrangeiros - políticos ou econômicos - que queiram enfraquecer a soberania brasileira. Quem cuida da Amazônia brasileira, a serviço da humanidade e de si mesmo, é o Brasil.

Além da Estratégia Nacional de Defesa, o Governo Federal instituiu o Plano Estratégico de Fronteiras para aumentar a segurança e defesa na faixa de fronteira do Brasil.

Revista Eletrônica da ANPHLAC, ISSN 1679-1061, n. 16, p. 6-25, Jan./Jul. 2014.

http://revista.anphlac.org.br 


\section{Plano Estratégico de Fronteiras}

O Plano Estratégico de Fronteiras (PEF) tem por objetivo o fortalecimento da prevenção, controle, fiscalização e repressão dos delitos transfronteiriços e dos delitos praticados na faixa de fronteira brasileira. Ele prevê a atuação integrada dos órgãos de segurança pública, da Secretaria da Receita Federal do Brasil e das Forças Armadas, podendo contemplar a participação de países vizinhos.

O Plano Estratégico de Fronteiras foi criado pelo Decreto n. 7.638 de 8 de dezembro de 2011, e possui as seguintes diretrizes:

- A integração das ações de segurança pública, de controle aduaneiro e das Forças Armadas da União com a ação dos Estados e Municípios situados na faixa de fronteira;

- A execução de ações conjuntas entre os órgãos de segurança pública, federais e estaduais, a Secretaria da Receita Federal do Brasil e as Forças Armadas;

- A troca de informações entre os órgãos de segurança pública, federais e estaduais, a Secretaria da Receita Federal do Brasil e as Forças Armadas;

- A realização de parcerias com países vizinhos;

- A ampliação do quadro de pessoal e da estrutura destinada à prevenção, controle, fiscalização e repressão de delitos na faixa de fronteira.

O PEF é colocado em prática pelo governo federal e intensificado com a realização das Operações Ágata, que são realizadas em determinadas áreas da fronteira com a participação das Forças Armadas e outros órgãos de segurança. A Operação Sentinela, assim como a Operação Ágata, tem por objetivo a defesa e a segurança do país.

A Operação Ágata, conduzida pelo Ministério da Defesa, e a Operação Sentinela, pelo Ministério da Justiça, são os vértices do PEF para o combate à criminalidade.

\section{Primeiras Edições da Operação Ágata: I, II e III}

A Operação Ágata 1 foi realizada entre Brasil e Colômbia na fronteira do estado do Amazonas, de 05 a 11 de agosto de 2011, na área do Comando Militar da Amazônia.

Revista Eletrônica da ANPHLAC, ISSN 1679-1061, n. 16, p. 6-25, Jan./Jul. 2014.

http://revista.anphlac.org.br 
Esta operação realizou-se em $1.699 \mathrm{Km}^{2}$. Contou com o seguinte efetivo de cada força: Marinha: 518 militares, Exército: 1.878 militares, e Aeronáutica: 442 militares.

A Operação Ágata 2 deu-se entre Brasil, Argentina, Uruguai e Paraguai nas fronteiras dos estados do Rio Grande do Sul, Santa Catarina e Paraná, de 12 a 26 de setembro de 2011, no Comando Militar do Sul, em uma área de $3.515 \mathrm{Km}^{2}$. Contou com o seguinte efetivo de cada força: Marinha: 592 militares, Exército: 6.905 militares, e Aeronáutica: 453 militares.

A Operação Ágata 3 ocorreu nas fronteiras do Brasil com Peru, Bolívia e Paraguai, de 22 de novembro a 06 de dezembro de 2011, no Comando Militar do Oeste. Cobrindo $6.418 \mathrm{Km}^{2}$. Contou com o seguinte efetivo de cada força: Marinha: 543 militares, Exército: 5.232 militares, e Aeronáutica: 802 militares.

Estas três primeiras operações atuaram em $11.632 \mathrm{Km}^{2}$ de fronteira, o que significa mais de $60 \%$ da extensão fronteiriça do Brasil. Foram empregados 63 navios e embarcações que patrulharam 45.406 Km de rios e lagos, fazendo 9.111 inspeções em embarcações que resultou em 46 apreensões e notificações.

Foram utilizadas 819 viaturas sobre rodas, 140 blindados, 28 helicópteros para fiscalizar produtos controlados, entre eles: pedreiras, fábricas e paióis, bem como pessoas físicas e jurídicas, bem como a fiscalização ambiental e madeireiras e garimpos ilegais, que resultou na apreensão de toras de madeira.Veículos leves, ônibus e caminhões também foram inspecionados, e resultou na apreensão de motos, carros, agrotóxicos, cocaína, maconha, contrabando e descaminho, armas de uso exclusivo das Forças Armadas, munições, explosivos, espoleta e cordel detonante.

A Aeronáutica empregou 109 aeronaves, feitas 205 patrulhas aéreas, 40 interceptações e executadas 4.213 horas de voo. A inspeção foi feita em aeronaves, pilotos e aeródromos. A ação cívico-social foi realizada por meio de atendimento médico e odontológico.

As três primeiras edições da Operação Ágata tiveram resultados positivos do ponto de vista militar devido à participação do Estado Brasileiro na faixa de fronteira: ao potencializar o poder das forças armadas nessa área, inibiu ação de organizações criminosas, além de exercitar a interoperabilidade entre as forças armadas e entre elas e os órgãos de segurança.

Revista Eletrônica da ANPHLAC, ISSN 1679-1061, n. 16, p. 6-25, Jan./Jul. 2014. http://revista.anphlac.org.br 
Em paralelo, as ações do Plano Estratégico de Fronteiras incluem a Operação Sentinela, encabeçada pelo Ministério da Justiça e com o apoio do Ministério da Defesa, tem foco de inteligência permanente da área de fronteira. Em contrapartida, a Operação Ágata é um evento de impacto pontual em um determinado período com a execução do Ministério da Defesa e o apoio do Ministério da Justiça. Para concluir o traçado da linha fronteiriça do Brasil, foi realizada a Operação Ágata 4, que contemplou a área da Amazônia setentrional.

\section{HISTÓRICO DAS OP. ÁGATA}

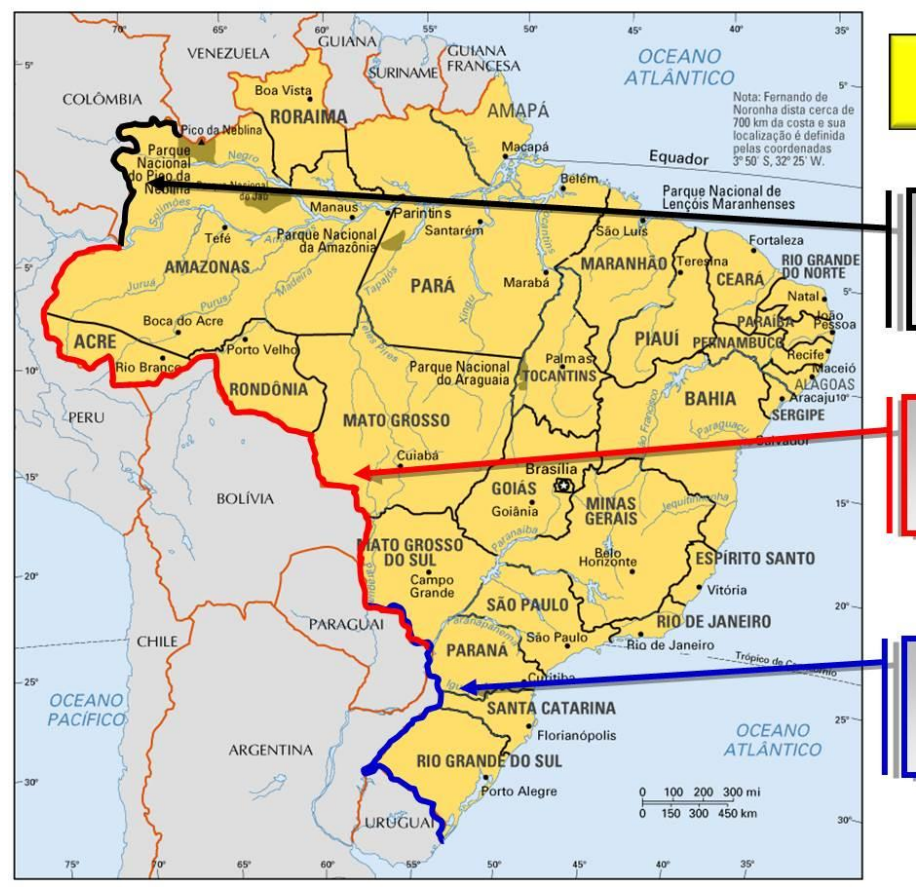

2011

ÁGATA 1

BRASIL - COLÔMBIA

ILUSTRAÇÃO 1_Ágata 1, 2 e 3

Fonte: Força Aérea Brasileira - Centro de Comunicação Social da Aeronáutica)

\section{Ágata 4}

De 02 a 17 de maio de 2012 ocorreu a Operação Ágata 4 que envolveu as fronteiras do Brasil com Guiana, Venezuela, Suriname e Guiana Francesa, abrangendo assim 5 países; 4 Estados; 40 municípios; foram $768.000 \mathrm{~km}^{2}$, sendo 9,1\% do Território Nacional, com extensão de $5.122 \mathrm{Km}$ de fronteiras.

Revista Eletrônica da ANPHLAC, ISSN 1679-1061, n. 16, p. 6-25, Jan./Jul. 2014.

http://revista.anphlac.org.br 


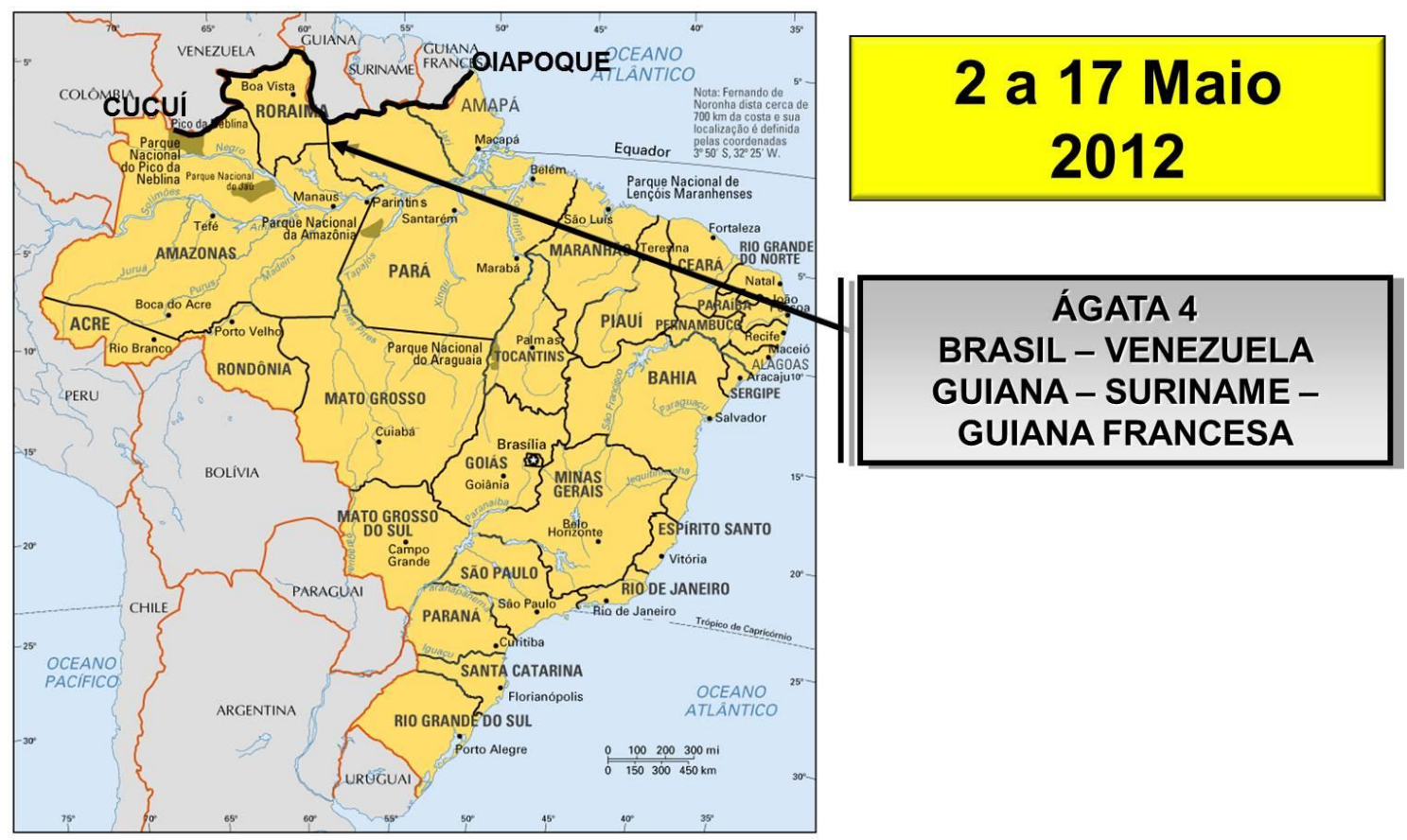

ILUSTRAÇÃO 2: Ágata 4

Fonte: Força Aérea Brasileira - Centro de Comunicação Social da Aeronáutica

Nesta região os tipos de crime são: contrabando de armas e munições; problemas indígenas; garimpo ilegal; contrabando de mineral radioativo; extração ilegal de madeira; e descaminho (principalmente de combustível / Venezuela).

Para planejar a Operação Ágata 4, foi necessário estudar a área da fronteira norte nos estados de Roraima, Amapá e Pará. Quanto ao relevo, a área em questão apresenta as serras de Pacaraima e Parima no estado de Roraima e a serra de Tucumaque no Pará e a Planície do Oiapoque no estado do Amapá. Hidrograficamente, é uma área bem abastecida de rios com o Rio Branco em Roraima, o rio Trombetas no Para e o rio Jari no Amapá, entre muitos outros afluentes.

A condução da Operação é feita seguindo-se a mesma estrutura que pode ser ativada em caso de conflito real, conforme um Teatro de Operações. O Centro de Operações Conjuntas (COC) do Ministério da Defesa é quem planeja as ações da Operação; o organograma apresenta o Comandante da Área de Operações, tendo como forças componentes: Força Naval Componente (FNC); Força Terrestre Componente (FTC), que estava representada pela Primeira Brigada de Infantaria de Selva e pela Revista Eletrônica da ANPHLAC, ISSN 1679-1061, n. 16, p. 6-25, Jan./Jul. 2014. 
Oitava Região Militar/DE; Força Aérea Componente (FAC); e o Comando de Defesa Aeroespacial Brasileiro (COMDABRA).

Houve a participação das seguintes instituições: Agência Brasileira de Inteligência (ABIN), Polícia Federal, Polícia Rodoviária Federal, Agência Nacional da Aviação Civil (ANAC), Receita Federal, Fundação Nacional do Índio (FUNAI), Instituto Brasileiro do Meio Ambiente e dos Recursos Naturais Renováveis (IBAMA), Instituto Chico Mendes de Conservação da Biodiversidade (ICMbio), Força Nacional de Segurança Pública e Sistema de Vigilância da Amazônia (Sivam).

No Centro de Operações Conjuntas, há representações do Ministério das Relações Exteriores, Ministério da Defesa, Ministério da Fazenda e Ministério de Minas de Energia. Também estão presentes no COC o Ministério da Justiça, Gabinete de Segurança Institucional da Presidência da República e o Ministério do Meio Ambiente, representados pelos seguintes órgãos: Departamento da Policia Federal, Departamentos de Polícias Rodoviárias estaduais, Secretaria Nacional de Segurança Pública, Força Nacional de Segurança Pública e os estados federados.

Entre os Objetivos da Ágata 4 estão a redução dos índices de criminalidade, coordenação do planejamento e execução de operações militares e policiais, cooperação com os países fronteiriços, intensificação da presença das Forças Armadas e apoio à população. A Operação tem por meta conhecer melhor a fronteira norte do país devido aos ilícitos que ocorrem na região.

A Operação foi realizada através de operações preventivas e repressivas, no período, na faixa de fronteira dos Estados da Amazônia, de Roraima, do Pará e do Amapá, por meio de patrulhamentos aéreos, terrestres e fluviais.

Entre as ações repressivas, estava a instalação de postos de bloqueio na calha dos rios e nas principais rodovias para a realização de revistas em embarcações, aeronaves, veículos automotores e motocicletas, bem como a destruição de pistas clandestinas usadas para o garimpo ilegal, muitas das vezes em área indígena.

Revista Eletrônica da ANPHLAC, ISSN 1679-1061, n. 16, p. 6-25, Jan./Jul. 2014. http://revista.anphlac.org.br 


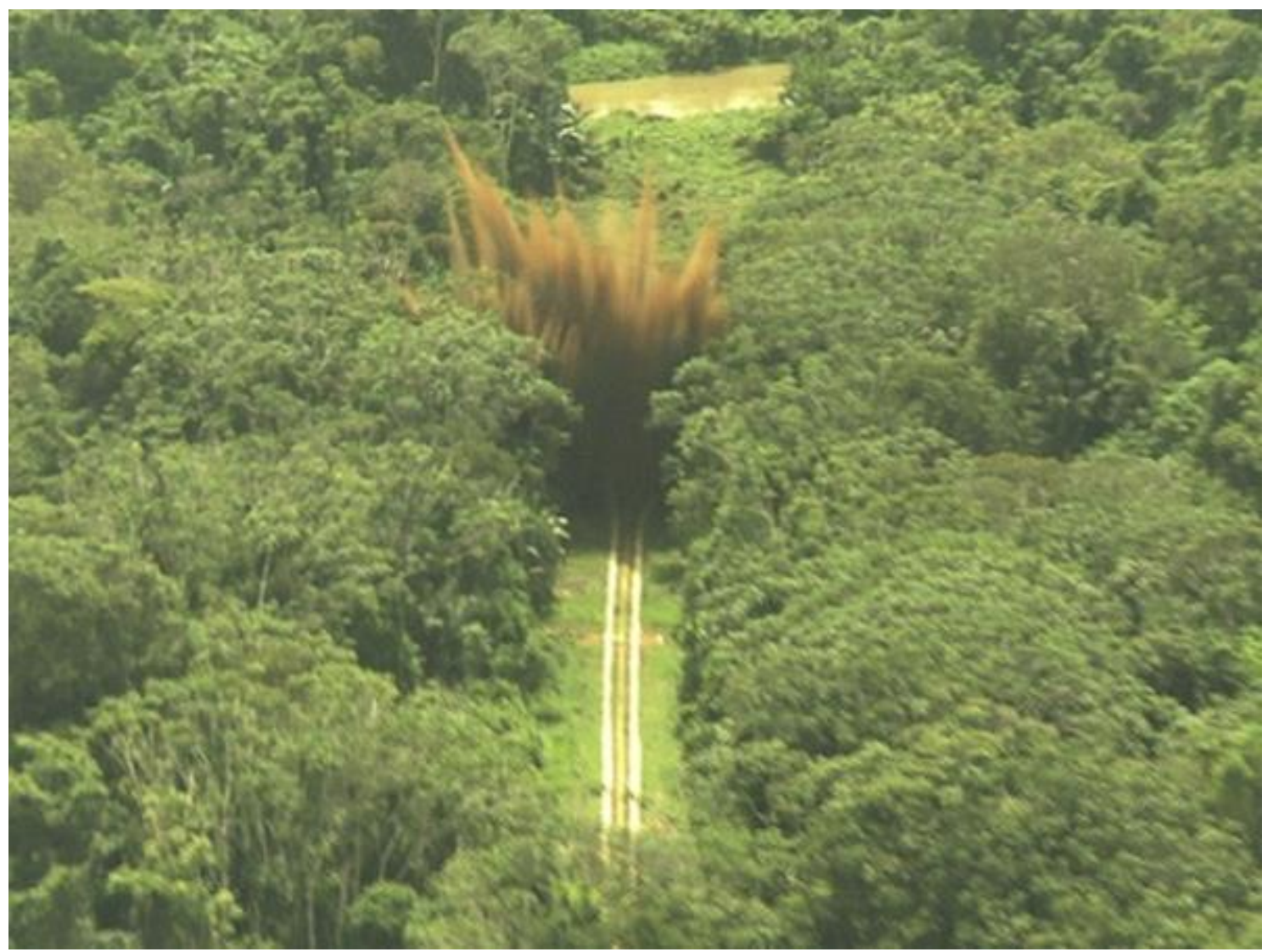

ILUSTRAÇÃO 3: Destruição de pista_

Fonte: Força Aérea Brasileira - Centro de Comunicação Social da Aeronáutica

Também foram realizadas Operações de Inteligência, atividades logísticas e de comunicações e Ações Cívico-Sociais entre a comunidade local, ribeirinhos e povos indígenas. Foram ações de apoio às populações residentes nas áreas de fronteiras. Todas estas ações foram possíveis por meio da integração e coordenação com os órgãos de segurança pública, agentes de fiscalização e de saúde dos Estados e de Organizações Não-Governamentais.

A primeira fase da missão deu-se com Operações de Inteligência, que contemplam informações prévias dos países fronteiriços e o emprego das Forças Armadas em coordenação com os Órgãos de Segurança Pública, garantindo a interoperabilidade defendida pelos documentos de defesa do Estado Brasileiro. Na segunda fase realizaram-se operações preventivas e repressivas em áreas previamente determinadas.

Revista Eletrônica da ANPHLAC, ISSN 1679-1061, n. 16, p. 6-25, Jan./Jul. 2014.

http://revista.anphlac.org.br 
A Força Aérea centrou sua missão em quatro pontos: mobilização aérea, ação social, tecnologia embarcada e emprego militar. Na mobilização aérea, a FAB empregou 1.700 militares, transportou 230 toneladas de carga e percorreu a distancia de 211.350 Km: esta extensão é o mesmo que dar quatro voltas em torno de nosso planeta, com uso conjunto de aeronaves e helicópteros.

$\mathrm{Na}$ ação social foi realizado atendimentos a populações carentes, distantes e ribeirinhas totalizando 4.257 atendimentos entre os quatro estados da federação. A FAB montou um hospital de campanha em uma balsa da Comissão de Aeroportos da Região Amazônica (COMARA) para atender as populações do interior e áreas de difícil acesso. Desta forma, diminuiu o tempo entre consultas e exames e procedimentos médicos. $\mathrm{O}$ Hospital contava com várias especialidades médicas e laboratórios para realização dos exames, sem a necessidade de deslocar o paciente para a cidade ou capital mais próxima.

Este hospital itinerante reduziu o tempo de diagnóstico, tratamento de doenças, bem como o custo de transporte e deslocamentos e atuou na carência de médicos em áreas afastadas.

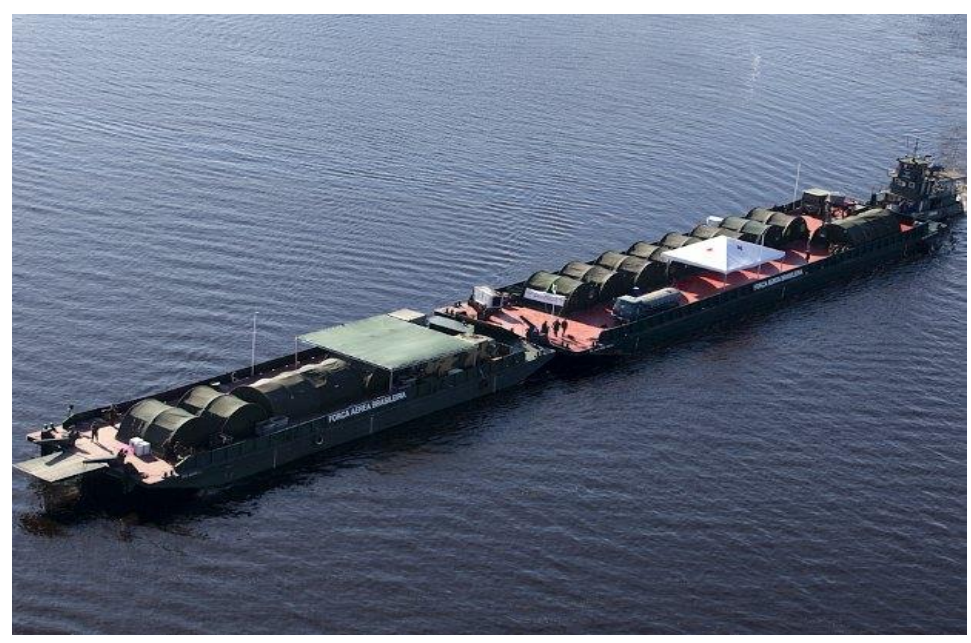

ILUSTRAÇÃO 4:Hospital de Campanha_

Fonte: Força Aérea Brasileira - Centro de Comunicação Social da Aeronáutica

Quanto à tecnologia embarcada, houve o uso de radares e fotos feitas pelas três forças. Foram sensoriadas 80 áreas de interesse com equipamentos radar, 
infravermelhos e ópticos. Através destes equipamentos, foram obtidas importantes informações sobre uma região de grandes riquezas e difícil acesso.

Em 10 dias de operações na Amazônia setentrional, 439 embarcações foram inspecionadas e vistoriadas, mais de dois mil carros e viaturas inspecionadas e vistoriadas, cerca de duzentas embarcações apreendidas, 18 acessos terrestres e fluviais controlados, feitas muitas inspeções com mais de 90 patrulhas e 521 apreensões de veículos e embarcações.

No que concerne às ações cívico-sociais, a Operação realizou um total de 2.568 atendimentos médicos, 1.460 atendimentos odontológicos, entre muitos outros atendimentos laboratoriais, exames ginecológicos, vacinações, intervenções cirúrgicas, exames dermatológicos e testes de HIV, eletrocardiograma e mamografia.

Foram entregues mais de vinte mil medicamentos à população carente e cadastradas 134 famílias no programa "Bolsa Família". O emprego militar aéreo foi realizado com reconhecimento aéreo, poder de ataque, controle e alarme em voo e posto de comunicação. As missões em solo eram de defesa e recurso isolado, ponto de bloqueio de vias, medidas de controle no solo e inspeção de aviação civil.

Com a realização das Operações Ágatas, as Forças Armadas e todos os órgãos de segurança nacional cumprem com a orientação das diretrizes de segurança nacional para ações conjuntas de interoperabilidade. Há, contudo, apreciações que revelam o pouco nível de desenvolvimento da interoperabilidade em operações fronteiriças, conforme a jornalista Denise Rothenburg:

Durante audiência pública promovida no Senado em novembro, o chefe do Centro de Comunicações e Guerra Eletrônica do Exército, general Antonino dos Santos Guerra, chegou a exemplificar a confusão que impera no setor. "Fazemos operações de fronteira que reúnem até 42 agências do Estado. É uma confusão. Ninguém fala com ninguém, não há interoperabilidade e o resultado é aquém do potencial." Melhor resumo da situação, impossível. (ROTHENBURG, 2013).

A Operação Ágata 4 ampliou os conhecimentos do Estado Brasileiro sobre a região amazônica, comtemplando aspectos físicos e populacionais. As fotos aéreas, em anexo no trabalho, mostram áreas de desmatamento, comunidades indígenas e

Revista Eletrônica da ANPHLAC, ISSN 1679-1061, n. 16, p. 6-25, Jan./Jul. 2014.

http://revista.anphlac.org.br 
populações ribeirinhas. A Amazônia é ainda no século XXI uma área desconhecida, onde se faz necessário maior número de incursões e estudos sobre a região.

Em contrapartida, o aspecto pontual, de curta duração, das edições da Operação Ágata suscita críticas quanto a sua real efetividade e eficácia, pois a ausência de ações contínuas - de custo exponencialmente mais elevado - prejudica a obtenção de resultados mais substanciais.

Considerando a extensão da faixa de fronteira, a carência da população, a baixa densidade demográfica, os ilícitos transnacionais, a diversidade de etnias indígenas, percebe-se a falta de políticas públicas consistentes para a região Amazônica. Quais as políticas públicas desenvolvidas na Amazônia? Quais diretrizes são colocadas em prática pelo governo brasileiro, quanto ao meio ambiente e a proteção ao índio? De que maneira o desenvolvimento poderá ser realmente sustentável? Quem ampara as comunidades ribeirinhas isoladas na imensidão amazônica?

A política pública desenvolvida para a defesa e segurança contempla uma reestruturação no Ministério da Defesa, que tendo um civil como ministro, passa a coordenar as Forças Armadas e diminuiu a autonomia de cada Força Armada, isoladamente. A recente criação do Estado-Maior Conjunto das Forças Armadas, pela Lei Número 136 de 2010, converge com as tendências mundiais de melhor coordenação entre as forças que passam a ter ações integradas.

O Projeto Amazônia Protegida é uma forma de fortalecer a presença militar na Amazônia e reforçar o patrulhamento da fronteira, sendo parte do plano de reorientação da doutrina militar brasileira. Assim, a Operação Ágata em suas diversas edições serve para o monitoramento das fronteiras em tempos de paz.

$\mathrm{Na}$ tentativa de assumir um papel relevante nas relações internacionais, o Brasil lança políticas públicas de segurança e defesa das fronteiras. Para ser um global player, necessita reorganizar e mobilizar as forças armadas e reforçar a presença militar na Amazônia, área prioritária, segundo a END.

A defesa e a segurança da região envolvem mais que proteção fronteiriça ou contenção de ilícitos transnacionais. A Amazônia comtempla meio ambiente, população indígena e ribeirinha e extração de recursos minerais, e embora as Operações Ágata desenvolvam ações sociais, estas são amplamente insuficientes para amenizar os

Revista Eletrônica da ANPHLAC, ISSN 1679-1061, n. 16, p. 6-25, Jan./Jul. 2014. 
problemas, as carências e as dificuldades logísticas enfrentadas pelos habitantes da região norte do país.

Eliézer de Oliveira $(2005$, p. 80$)$ reclama da superficialidade que é tratada a questão de defesa pelo poder político no Brasil, ao afirmar que "faltam aos dirigentes políticos e a opinião pública o conhecimento e a valorização da defesa nacional (...)”. Nesta mesma direção, Adriana Marques (2006, p. 69) afirma que há pouca gerência do poder legislativo sobre as políticas públicas voltadas para defesa: "Os estudos sobre as relações civis-militares no Brasil, em sua maioria, destacam a inoperância do poder legislativo no que se refere à temática da defesa nacional."

Embora os governos de Fernando Henrique Cardoso (1995-2003) e Luís Inácio da Silva (2003-2010) tenham elaborado políticas para repensar a segurança e a defesa do Brasil, as propostas e planos executados ainda são muito tímidos e se traduzem em poucos resultados para as questões que merecem ser prioritárias na agenda brasileira.

\section{Conclusão}

Como visto, a Amazônia é um construto ocidental que perdeu sua vocação para a cooperação e integração. Essas virtudes eram comuns às sociedades andinas e amazônicas do período pré-incaico ao contrário do que as versões tradicionais afirmam sobre a região em pauta.

Com a inserção da cultura europeia, o equilíbrio de poder dos povos nativos é destruído e não se logra um novo equilíbrio. A partir das independências sul-americanas e o advento dos Estados nacionais, criam-se "vácuos de poder", os quais são aproveitados por agentes dos ilícitos em fronteiras desprotegidas ou mal protegidas.

Entre os crimes transnacionais que preocupam as autoridades brasileiras estão: tráfico de drogas e armas, pirataria, busca internacional por conhecimentos na área de biodiversidade, principalmente para a indústria farmacêutica, tráfico de pessoas, garimpo ilegal, entre outros. O Brasil, segundo a END, reconhece estes ilícitos como ameaças à Nação e não aponta nenhum país como inimigo externo.

A preocupação nacional com a Amazônia a coloca em destaque nos documentos oficiais e transfere número maior de militares das três forças para a guarnição e defesa da região. O perigo hoje transcende a invasão armada do país ou mesmo envolve Revista Eletrônica da ANPHLAC, ISSN 1679-1061, n. 16, p. 6-25, Jan./Jul. 2014. 
questões de limites. $\mathrm{O}$ inimigo ora se representa na atuação de organizações que visam a atender interesses estrangeiros em solo brasileiro e nos crimes, delitos e violações de toda ordem.

As novas diretrizes da política externa brasileira e o não alinhamento direto com grandes potências obrigam o Brasil a repensar sua defesa e a estabelecer novas políticas governamentais. O novo paradigma de desenvolvimento sustentável, com a proteção ao meio ambiente, à fauna e à flora, demanda medidas mais abrangentes que a simples criação de área de reservas ambientais.

Da mesma forma, a proteção ao índio exige iniciativas que transcendam a demarcação de terras e a criação de reservas, pois a população indígena tem direito à autodeterminação e à cidadania.

A falta de políticas públicas para a Amazônia favorece o número crescente de ilícitos, pobreza e abandono. A presença do Estado aumenta, por vezes, por intermédio das operações militares de segurança, defesa e assistência social. A interoperabilidade entre as Forças Armadas e os órgãos de segurança pública é imprescindível para a defesa e segurança em áreas de vulnerabilidade como a floresta Amazônica.

\section{Referências Bibliográficas:}

ALMEIDA, Paulo Roberto de. Uma política externa engajada: a diplomacia do governo Lula. Revista Brasileira de Política Internacional, 47 (1), p. 162-184, 2004.

BUZAN, Barry; HANSEN, Lene. The evolution of international security studies. New York: Cambridge University Press, 2009.

BRASIL. Constituição (1988). Constituição da República Federativa do Brasil. Brasília, DF, Senado, 1988.

CASTRO, Celso (org). Amazônia e defesa Nacional. Rio de Janeiro: FGV, 2006.

COLLINS, Alan. Contemporary security studies. Oxford: Oxford University press.

COSTA, Kelerson Semerene. Apontamentos sobre a formação histórica da Amazônia: uma abordagem continental. Série de Estudos e Ensaios/Ciências Sociais/FLACSOBrasil - junho/2009, p. 1-25

Revista Eletrônica da ANPHLAC, ISSN 1679-1061, n. 16, p. 6-25, Jan./Jul. 2014. http://revista.anphlac.org.br 
FREITAS, Robson Rodrigues. A aviação de caça no policiamento da Amazônia: hipótese de aplicação do poder de polícia pela Força Aérea Brasileira. Boa Vista: UFRR, 2011.

GAMA, Marcos Vinicius Pinta. O Conselho de Defesa Sul-Americano e sua instrumentalidade. In: JOBIM, Nelson. et al. Segurança Internacional: perspectivas brasileiras. Rio de Janeiro: FGV, 2010.

JOBIM, Nelson. Et al. Segurança Internacional: perspectivas brasileiras. Rio de Janeiro: FGV, 2010.

JUNGMANN, Raul. Estratégia Nacional de Defesa. In: In: JOBIM, Nelson. et al. Segurança Internacional: perspectivas brasileiras. Rio de Janeiro: FGV, 2010.

MARQUES, Adriana. Presença militar na Amazônia: a visão do Poder Legislativo. In: CASTRO, Celso. Amazônia e Defesa Nacional. Rio de Janeiro: FGV,2006.

MATOS, Carlos de Meira. Uma geopolítica pan-amazônica. Rio de Janeiro: J. Olympio; Brasília: INL, 1980.

OLIVEIRA, Eliézer Rizzo de. Democracia e Defesa Nacional: a criação do Ministério da defesa na presidência de FHC. Barueri: Manole, 2005.

PROCÓPIO, Argemiro. Subdesenvolvimento sustentável. $2^{\mathrm{a}}$ ed., Curitiba: Juruá, 2008.

ROTHENBURG, Denise. Forças desafinadas. In: Correio Braziliense, Brasília, 30 dez. 2013.

VILLAS BÔAS, Eduardo. Construindo hipóteses de emprego na Amazônia. In: JOBIM, Nelson. et al. Segurança Internacional: perspectivas brasileiras. Rio de Janeiro: FGV, 2010.

\section{Documentos}

Estratégia Nacional de Defesa

Plano Estratégico de Defesa

\section{Entrevista}

Entrevista concedida pelo Brigadeiro do Ar Marcelo Kanitz Damasceno, chefe do centro de Comunicação Social da Aeronáutica (CECOMSAER) em abril de 2013, no Edifício do Comando da Aeronáutica em Brasília-DF. O Brigadeiro Damasceno foi o Comandante da Força Aérea Componente na Operação Ágata 4. 


\section{Sites:}

http://www.defesanet.com.br/fronteiras/noticia/5991/AGATA-4---Balanco-da-Operacao https://conteudoclippingmp.planejamento.gov.br/cadastros/noticias/2013/12/30/forcasdesafinadas

Revista Eletrônica da ANPHLAC, ISSN 1679-1061, n. 16, p. 6-25, Jan./Jul. 2014. http://revista.anphlac.org.br 